\title{
Physical ageing of epoxy in a wet environment: Coupling between plasticization and physical ageing
}

\author{
Le Guen-Geffroy Antoine ${ }^{1,{ }^{*}}$, Le Gac Pierre Yves ${ }^{1}$, Habert B. ${ }^{2}$, Davies Peter ${ }^{1}$
}

\begin{abstract}
${ }^{1}$ Laboratoire de comportement des structures en mer, Ifremer, Marine Structures Laboratory, ZI de la pointe du diable, CS10070, 29280, Plouzané, France

2 IP/MCM/PMA, Direction Générale de l'Armement, PC62, 60 boulevard du Général Valin, 75015, Paris, France

* Corresponding author : Antoine Le Guen-Geffroy, email address : Antoine.le.guen.geffroy@ifremer.fr
\end{abstract}

\begin{abstract}
:
This paper shows how physical ageing and plasticization processes are coupled in an amine-based epoxy. The study combines several ageing conditions including thermal ageing in the dry state (from 40 to $60{ }^{\circ} \mathrm{C}$ ), ageing in a humid environment ( $\mathrm{RH} 50 \%$ and $\mathrm{RH} 75 \%$ ) as well as immersion in seawater at several temperatures from 15 to $40^{\circ} \mathrm{C}$. First results are presented to highlight that the two processes (physical ageing and plasticization) both occur when the epoxy is immersed in water. A step-by-step approach is then used to evaluate how the plasticization process induced by the presence of water is affected by physical ageing and vice versa. It appears that the plasticization process, which leads to a large decrease in maximum stress under tensile loading, is not affected by physical ageing of the epoxy. The physical ageing mechanism is not affected by the presence of water in the polymer, i.e. the same increase in maximum tensile stress (26 MPa) is observed in air and in water. However, the kinetic rate of physical ageing is much faster in water due to the plasticization of the polymer. These effects must be considered when accelerated aging methods are applied.
\end{abstract}

\section{Highlights}

- Plasticization process induced by water absorption is not greatly affected by physical ageing. Physical ageing process occurs in both dry and humid environments. Physical ageing is much faster in the presence of water (by a factor of 10 ).

Keywords : Epoxy, Physical ageing, Water, Plasticization 


\section{Introduction}

Epoxy materials are widely used in the marine domain as coatings [1,2], adhesives $[3,4]$ and as a matrix for many composite materials [5-8]. Because long term durability is mandatory for structures used at sea for both ecological and economic reasons, the durability of epoxy polymers in a humid environment has been widely studied in the past [9-12].

When epoxy materials are immersed in seawater, water diffuses into the polymer. This water absorption usually follows a Fickian behaviour that allows a maximal water absorption and a diffusion rate to be defined. The water absorption depends largely on chemical formulation, especially the type of hardener $[13,14]$. For amine-based epoxies, maximal water uptake is roughly $3 \%[11,15-17]$ with a low water diffusion rate being between 1 and $3.10^{-13} \mathrm{~m}^{2} / \mathrm{s}$ for amine based epoxies $[15,16,18-20]$ compared to the anhydride-based epoxies for which the water uptake is low, about $0.5 \%$ [21]. The presence of water within the epoxy leads to a physical and reversible degradation known as plasticization, by which water leads to an increase in macromolecular chain mobility. This process is mainly observed in amine-based epoxy materials, due to the large amount of absorbed water. The increase in chain mobility leads to a large decrease in glass transition temperature $(\mathrm{Tg})$, about $10^{\circ} \mathrm{C}$ per percent of water in the epoxy, and large changes in mechanical behaviour $[9,11,18,19,22]$. The most impressive consequence is the decrease in yield stress, that can be divided by a factor of 2 due to water absorption [23,24]. The presence of water can also leads to an increase in strain at break [25]. In terms of modulus, both increases and decreases can be observed depending on the anti-plasticization effect $[26,27]$.

It is also well known that polymers can undergo physical ageing when used below their $\operatorname{Tg}[28,29]$. This kind of ageing is the result of a reduction in free volume and changes in the molecular configuration. Since this process has been widely studied, most of the results available are well reviewed in [30]. One need only recall that physical ageing is a reversible process that occurs with time and can be erased by heating samples above $\mathrm{Tg}$, a process known as thermal rejuvenation. Physical ageing leads to a small increase in $\operatorname{Tg}$ (about $5^{\circ} \mathrm{C}$ ) and a large increase in yield stress. For example, Cook et al. found an increase from $50 \mathrm{MPa}$ to $80 \mathrm{MPa}$ during physical ageing of an epoxy[31]. Although this process has been widely studied in the past, most of the results available come from experiments performed in air. When considering coupling between water absorption and physical ageing, few results are available. Zheng et al. [32] were the first to study the impact of water content on physical ageing through volume variation measurements. They found that water content has similar effects to temperature changes on physical ageing of epoxy but kinetics are different, which leads to difficulties in prediction; they did not consider mechanical changes induced by physical ageing. Here we focus on changes in yield stress of an epoxy during ageing in seawater where both plasticization and physical ageing occurs.

First, material and methods are presented. Then we will focus on primary results that clearly show that both physical ageing and plasticization occur when the epoxy is immersed in seawater. Based on these results, a step-by-step methodology will be used to highlight coupling between these two phenomena. Finally, a conclusion will be made. 


\section{Materials and methods}

\section{a. Materials}

The material studied is a commercial epoxy resin SR8100 from Sicomin ${ }^{\circledR}$ with an amine based slow hardener SD4772 which is suitable for Resin Transfer Moulding (RTM) and infusion processing of composites. The pre-polymers are diglycidyl ether of bisphenol $F$ (DGEBF, $\geq 50 \%$ ), diglycidyl ether of bisphenol A (DGEBA, $\geq 10 \%$ ) and 1,6 hexa diglycidyl ether ( $\geq 10 \%)$.

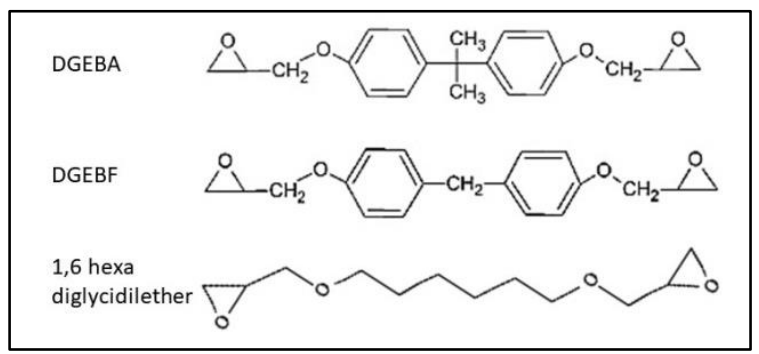

Figure 1: Molecular structures of pre-polymer

\section{b. Sample preparation and fabrication}

Resin was cast vertically between two aluminium plates separated by an all-around $3 \mathrm{~mm}$ thick spacer. This thickness was chosen to allow an easier casting due to the resin's viscosity. This casting technique allows low surface contact with ambient air limiting unwanted reactions during curing of the resin. After 24 hours at ambient room temperature, the resin plates were removed from the mould, aluminium plates were covered by Teflon tape in order to assist removal of the epoxy plates. Then epoxy sheets were placed in vacuum bags and cured for 16 hours at $60^{\circ} \mathrm{C}$ as recommended by the supplier. Finally, the resin plates were post-cured for 2 hours at $120^{\circ} \mathrm{C}$ allowing full curing of the resin. The resulting glass transition temperature $(\mathrm{Tg})$ was measured by $\mathrm{DSC}$ at $10^{\circ} \mathrm{C} / \mathrm{min}$ with a TA instruments Q200 DSC at $75^{\circ} \mathrm{C}$.

After curing, resin plates were machined down to $1 \mathrm{~mm}$ in thickness and tensile specimens were cut in accordance with 1BA dimensions from ISO 527-2 with a Charly DMC 300 CNC machine from Charly Robot $^{\circledR}$.

\section{c. Tensile procedure and measurements}

Tensile tests were performed according to ISO $527-2$ under displacement control at $1 \mathrm{~mm} / \mathrm{min}$ on a $10 \mathrm{kN}$ Instron ${ }^{\mathrm{TM}}$ machine, with a $500 \mathrm{~N}$ Instron ${ }^{\mathrm{TM}}$ load cell and pneumatic grips. Tests were carried out in a $21^{\circ} \mathrm{C} 50 \% \mathrm{RH}$ controlled room. Strain measurements were obtained by digital image correlation by applying a random graphite pattern on the specimens. Images were captured by a Basler ${ }^{\mathrm{TM}}$ camera at $^{2}$ 1 frame per second and correlated with Aramis $^{\circledR}$ software.

\section{d. DMA}

DMA were performed using a Metravib ${ }^{\text {TM }} 150 \mathrm{~N}$ machine in tensile mode with a dynamic strain of 5.104 and a ratio between static and dynamic displacement equal to 4 . Samples were tested at $1 \mathrm{~Hz}$ from $120^{\circ} \mathrm{C}$ to $200^{\circ} \mathrm{C}$ with a temperature increase of $2^{\circ} \mathrm{C} / \mathrm{min}$. 


\section{e. Physical ageing procedure}

For physical ageing in dry environment: Tensile specimens were first packed in vacuum bags in order to limit any oxidative reactions. Before any physical ageing, bags were placed in $90^{\circ} \mathrm{C}$ water for 5 minutes in order to expose specimens to above-Tg temperature and thus eliminate any physical ageing present in the material. Then specimens were immediately quenched by plunging the vacuum bags in $15^{\circ} \mathrm{C}$ water. Quenched samples were then placed in different temperature ovens. Before being tested in tension, samples were placed in the testing room for at least 15 minutes in order to cool to room temperature.

For physical ageing in wet environment: The tensile samples were first immersed in seawater at $40^{\circ} \mathrm{C}$ during one month, which corresponds to full saturation at $2.8 \%$ by weight of water. Samples were then placed in $90^{\circ} \mathrm{C}$ water for 5 minutes and quenched in $15^{\circ} \mathrm{C}$ water in order to erase any physical ageing present in the material. The samples were finally placed in different temperature-controlled seawater baths. This results in physical ageing without changing the water content inside the material.

\section{f. Water ageing in air and in seawater}

Water ageing was performed under three different humidity conditions and one temperature of $40^{\circ} \mathrm{C}$. The $50 \%$ and $75 \%$ relative humidity conditions were applied in temperature and humidity controlled ovens, and natural seawater ageing was performed in a renewed, and temperature controlled natural seawater bath. For more details on the facility used see [33]. 


\section{Results and discussion}

\section{Preliminary tests and resulting coupling problematic}

This first experimental results section aims to highlight the fact that both plasticization and physical ageing occur when amine based epoxy materials (see Fig. 1) are immersed in seawater. Figure 2 shows tensile curves obtained on unaged and aged samples at $40^{\circ} \mathrm{C}$ in seawater, i.e. below $\mathrm{Tg}$, for 1 month until saturation occurs. After ageing, samples were tested after several treatments.

First, the tensile behaviour of the unaged sample (\#1 in Figure 2) shows a typical elastoplastic behaviour with a linear part for low strain with a modulus close to $2.6 \mathrm{GPa}$ then a yield that is related to the maximal stress (here $57 \mathrm{MPa} \pm 1$ ) and finally a failure that occurs at roughly $10 \%$ elongation. All these values are typical for epoxy materials [8].

Then, samples were tested directly after removal from ageing tanks meaning that they are fully saturated by water ( $2.8 \%$ here), this is curve \#2. It clearly appears that tensile behaviour is affected by ageing here. In fact, an increase in maximal stress from $57 \mathrm{MPa}$ to $64 \mathrm{MPa}$ is noted when water is in the epoxy material. A large decrease in maximal elongation is observed.

When water is removed, i.e. samples dried at $40^{\circ} \mathrm{C}$ with a relative humidity equal to $0 \%$, a larger increase in maximal stress is observed, see curve \#3 in Figure 2. In this case, maximal stress is equal to $76 \mathrm{MPa}$, which is $19 \mathrm{MPa}$ more than for the unaged epoxy. Here again elongation is low.

At this stage, it appears that after 1 month at $40^{\circ} \mathrm{C}$ in seawater, epoxy samples are saturated by water up to $2.8 \%$ and tensile behaviour is strongly affected by ageing with a large increase in maximal stress and a decrease in elongation at break. Moreover, it appears that when samples are dried, we enhance the increase in maximal stress. This fact suggests that, as expected, matrix plasticisation by water plays a role in the tensile behaviour of the material.

In order to fully understand these results, samples after ageing in seawater at $40^{\circ} \mathrm{C}$, have been subjected to a short ( 5 minutes) immersion at $90^{\circ} \mathrm{C}$ in seawater which will be referred as rejuvenation further in this article. This immersion above $\mathrm{Tg}$ aims to remove any physical ageing of the epoxy without changing the water content in the material. After this thermal treatment, tensile tests were performed with the presence of water in the polymer and results are presented on curve \#4. We clearly see that the thermal treatment of saturated samples leads to a large decrease in maximal stress (from $62 \mathrm{MPa}$ before thermal treatment to $40 \mathrm{MPa}$ after). In the meantime, maximal elongation is largely improved due to plasticization of the matrix by water. Based on these results it is obvious that physical ageing is involved in the changes observed in mechanical behaviour of this epoxy when immersed below $\mathrm{Tg}$.

Both plasticization and physical ageing are macroscopically reversible processes. They are removed respectively by drying samples and thermal treatment above Tg. In order to check if any irreversible degradation occurs during immersion at $40^{\circ} \mathrm{C}$, samples were exposed to thermal treatment after being fully dried and then tested. Results obtained are also plotted in Figure 2 (curve \#5). We can see that results are similar to those for unaged sample, both in terms of yield stress and maximal elongation. It can be thus concluded that no irreversible degradation occurs when this fully cured amine based epoxy is immersed at $40^{\circ} \mathrm{C}$ in seawater. 


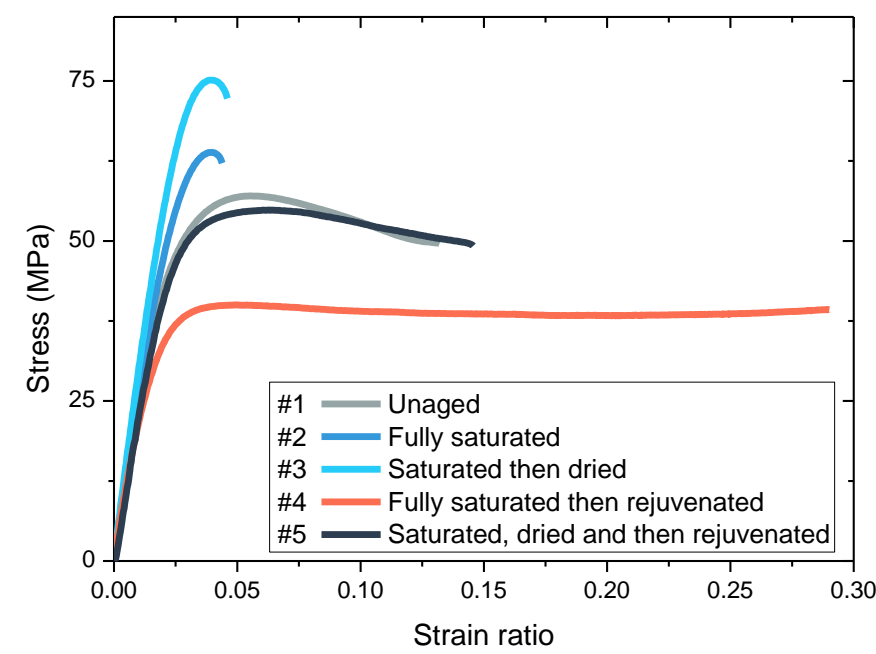

Figure 2: Tensile behaviour of saturated and dried epoxy resin exposed to $40^{\circ} \mathrm{C}$ seawater

As a conclusion to this first part of the study, it appears that maximal stress (the property of interest here) is strongly affected by two reversible processes when this epoxy is immersed in seawater: matrix plasticization and physical ageing. The next parts of this paper will focus on the study of the coupling between these two reversible processes. In the meantime, we have shown that there is no macroscopically irreversible degradation involved here. 


\section{i) Plasticization of the resin when physical ageing is removed}

This section is devoted to the plasticization of the epoxy material induced by the presence of water between macromolecular chains. First, we will consider water absorption in the polymer at $40^{\circ} \mathrm{C}$, then changes in $\mathrm{Tg}$, and finally the impact of water content on tensile behaviour.

\section{- Water uptake}

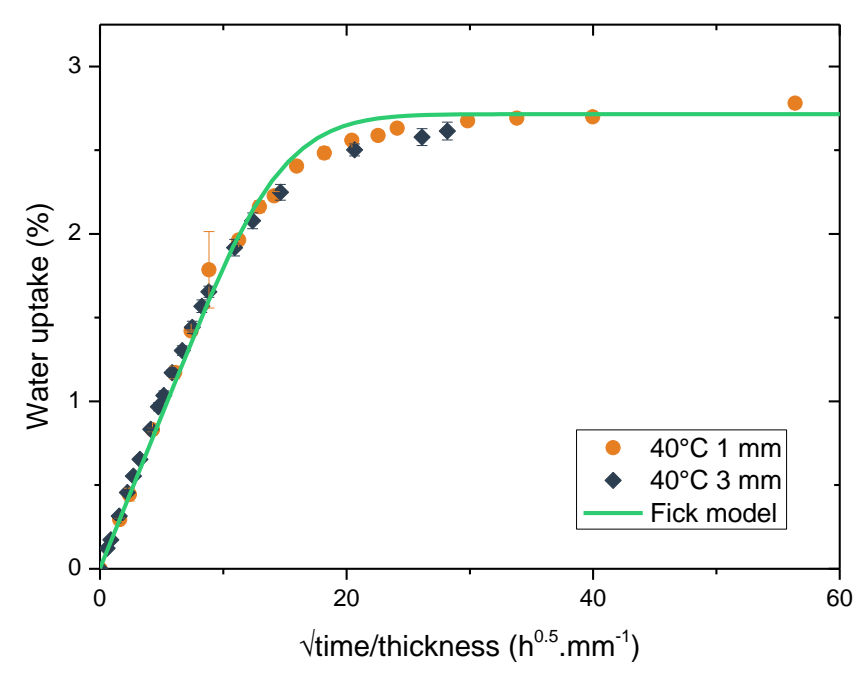

Figure 3 Fickian diffusion of the resin at $40^{\circ} \mathrm{C}$ in seawater

In order to avoid any complexity with water profile through the thickness but to be able to assess the behaviour of the epoxy containing different amounts of water, samples have been aged in seawater as well as under 50 and $75 \%$ relative humidity. In all cases, a Fickian behaviour is observed with water diffusion coefficient $D$ equal to about $4.10^{-13} \mathrm{~m}^{2} / \mathrm{s}$, which is in accordance with data from literature $[18,19,22]$. As an example, the water uptake measured at $40^{\circ} \mathrm{C}$ in seawater is shown in Figure 3 . In our case, for $1 \mathrm{~mm}$ thick samples, time to saturation is about 22 days. The maximal water uptake in the resin obviously depends on the water activity of the surrounding environment[19]; data are available in Table 1. In seawater a maximal water uptake of $2.7 \%$ is observed, this is a typical value for amine based epoxy [14].

\begin{tabular}{c|c}
\multicolumn{2}{c}{$\begin{array}{c}\text { Maximal water content } \\
(\%)\end{array}$} \\
\hline SEAWATER & 2.7 \\
75\% RH & 1.7 \\
$\mathbf{5 0 \%}$ RH & 1 \\
\hline
\end{tabular}

Table 1: maximal water content at saturation for different ageing condition.

\section{- Glass transition temperature}

Because water leads to an increase in mobility of macromolecular chains, we usually observe a decrease in the $\mathrm{Tg}$ of the polymer as shown in Figure 3. Here $\mathrm{Tg}$ drops from $75^{\circ} \mathrm{C}$ to $61^{\circ} \mathrm{C}$ when $2.7 \%$ of water is absorbed. Moreover, it has been shown that $\mathrm{Tg}$ reduction as a function of water content can be calculated using the Simha-Boyer equation [34-36] : 


$$
\begin{gathered}
\frac{1}{T_{g}}=\frac{1}{T_{g p}}+A \times \vartheta_{\mathrm{H}_{2} O} \\
\text { With } A=\frac{1}{T_{g s}}-\frac{1}{T_{g p}}
\end{gathered}
$$

Where $T_{\mathrm{g}}$ is the glass transition of the material with a known value of water, $T_{\mathrm{gp}}$ is the glass transition of the polymer without any water previously measured at $348 \mathrm{~K}, \mathrm{~T}_{\mathrm{gs}}$ is the solvent glass transition that is water in our case taken at $136 \mathrm{~K}[37,38]$ and $\vartheta_{\mathrm{H}_{2} \mathrm{O}}$ being the volume ratio of water in the material.

Both experimental data and prediction are plotted in Figure 4. It appears that it is possible, based on the Simha-Boyer equation, to describe the decrease in Tg induced by the presence of water within this epoxy.

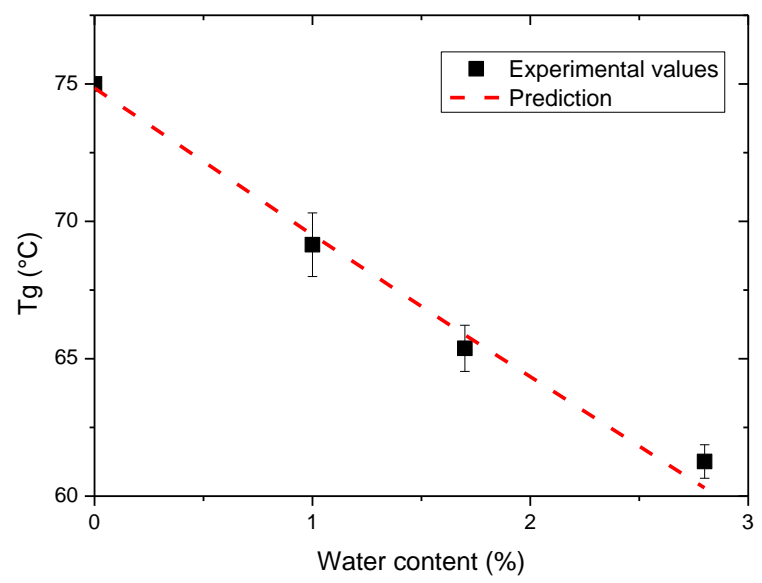

Figure 4: Comparison of experimental measurements of $\mathrm{Tg}$ and theoretical Simha-Boyer values

\section{- $\quad \underline{\text { Tensile properties }}$}

Figure 5 shows the tensile behaviour of the epoxy when physical ageing is removed. Samples were aged under different water ageing conditions and, prior to tensile testing, exposed for 5 minutes at $90^{\circ} \mathrm{C}$. One can observe the characteristic effect of plasticization as maximal stress decreases while water quantity increases. It may be noted that an increase in water content also leads to an increase in strain at break. When water is removed, tensile behaviour is the same as for the unaged sample showing that no irreversible degradation occurs. 


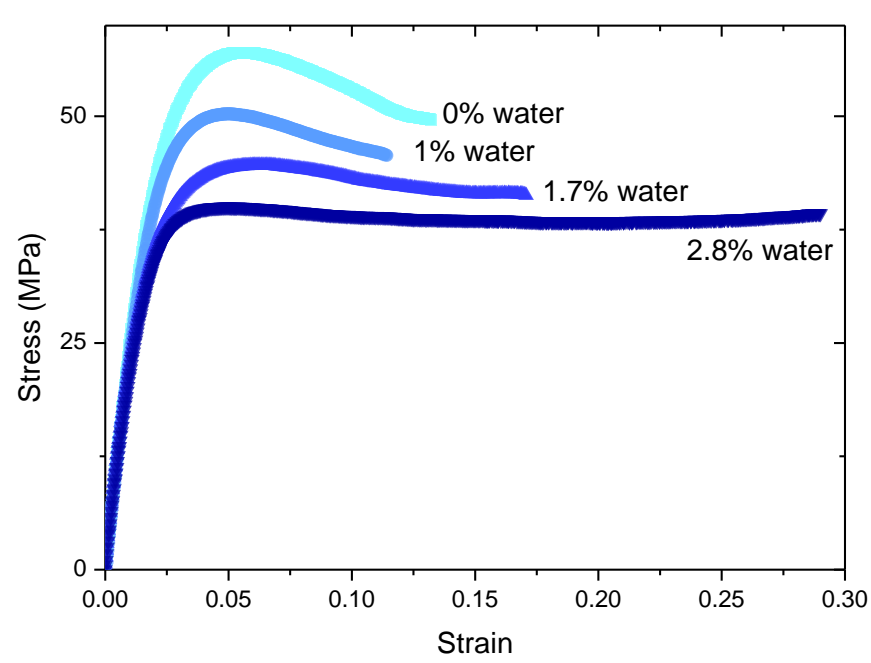

Figure 5: Effect of water content on tensile behaviour when physical ageing is removed

These results clearly confirm that plasticization leads to large changes in tensile properties of amine based epoxy. One of the remaining questions here is how this plasticization process is affected by physical ageing in the material. To answer this question it is necessary to decouple the two processes. To do so, in the next section we will study the plasticization process with samples that have been previously aged physically in a dry environment.

\section{ii) Physical ageing in a dry environment}

Physical ageing of epoxy material in dry environment has been described in detail in the literature $[28,29]$. Here sub-Tg ageing has been performed on tensile specimens in the dry state under inert atmosphere at three different temperatures $\left(40,50\right.$, and $\left.60^{\circ} \mathrm{C}\right)$ for several durations. After ageing, samples were cooled to $21^{\circ} \mathrm{C}$ and characterized. Results obtained at $40^{\circ} \mathrm{C}$ are plotted in Figure 6 . During ageing, large mechanical changes occur; as expected an increase of maximal stress is observed (from $57 \mathrm{MPa}$ to $82 \mathrm{MPa}$ ) as well as a decrease in elongation at break.

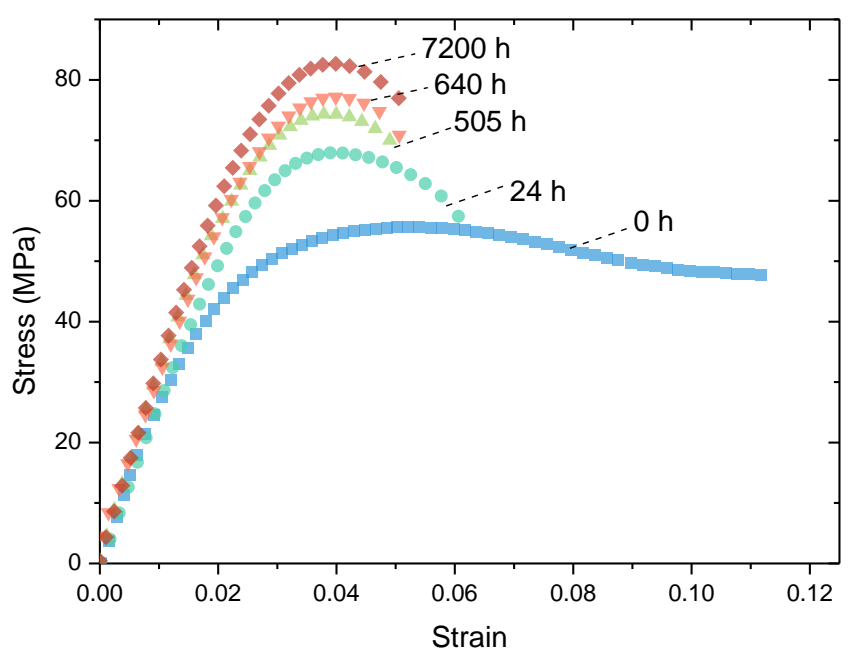


At 50 and $60^{\circ} \mathrm{C}$, the same behaviour is observed but the higher the temperature is, the faster the increase in maximal stress, as shown in Figure 7. Let us focus now on the mathematical description of the increase in maximal stress over time for the three different temperatures considered here, in order to be able to compare kinetic rates in air and in water (see later).

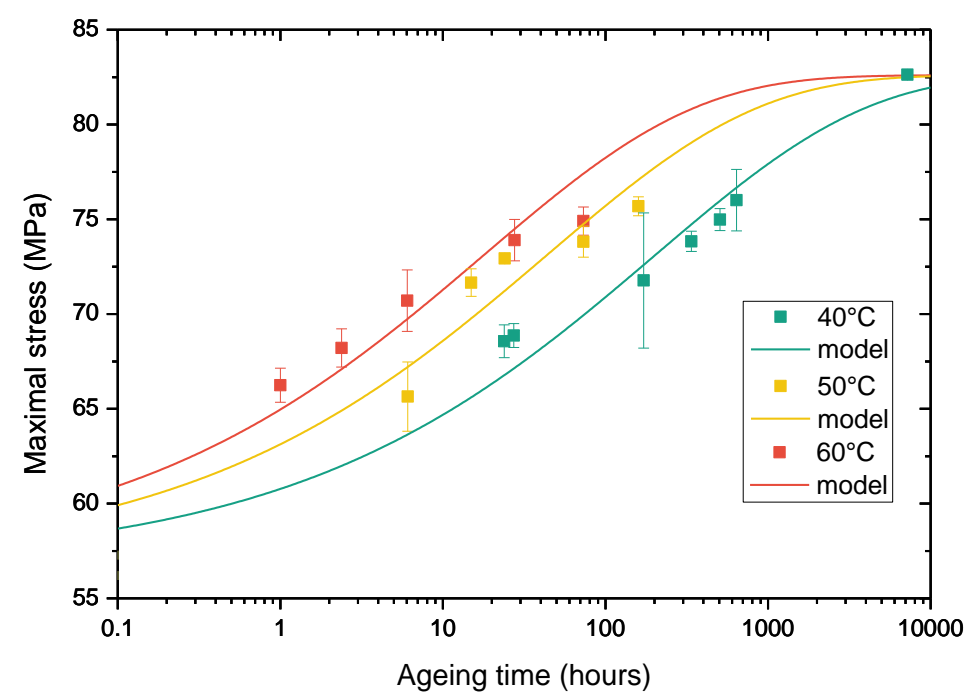

Figure 7: Maximal stress as a function of sub-Tg ageing time at $60^{\circ} \mathrm{C}\left(\right.$ red), $50^{\circ} \mathrm{C}$ (yellow) and $40^{\circ} \mathrm{C}$ (green)

It has been shown many times $[28,30,32,39]$ that the increase in maximal stress during physical ageing of a polymer can be described by a modified Kohlrausch-Williams-Watts (KWW) equation, as:

$$
\sigma_{y}(t)=\sigma_{0}+\Delta_{\sigma}\left(1-e^{-\left(\frac{t}{\tau}\right)^{\beta}}\right)
$$

Where $\sigma_{\mathrm{y}}$ is the maximal stress at a time $\mathrm{t}, \sigma_{0}$ is the maximal stress in the unaged state (57 MPa here), $\Delta_{\sigma}$ is the maximal stress increase (equal to $26 \mathrm{MPa}$ here), $\mathrm{t}$ is ageing time, $\beta$ the stretching parameter (fixed at $1 / 3$ here based on published results with epoxy [39]) and $\tau$ is a relaxation time that depends on material and ageing conditions.

Using equation (3) and data plotted in Figure 6 it is possible to describe the increase in maximal stress with ageing time in air by adjusting the value of $\tau$. Results are shown in Table 2 . An increase in ageing temperature leads to an acceleration of the ageing process meaning a decrease in the relaxation time. Temperature dependence of the relaxation time can be described by an Arrhenius plot, see Figure 8 . The activation energy, in a dry environment, is equal to $106 \mathrm{~kJ} / \mathrm{mol}$.

\begin{tabular}{c|c|} 
& $\tau(\mathrm{h})$ \\
\hline $\mathbf{6 0} 0^{\circ} \mathbf{C}$ & 18 \\
$\mathbf{5 0} \mathbf{C}$ & 43 \\
$\mathbf{4 0} \mathbf{C}$ & 199
\end{tabular}

Table 2: $\tau$ values obtained during physical ageing of the amine based epoxy in dry environment as a function of temperature. 


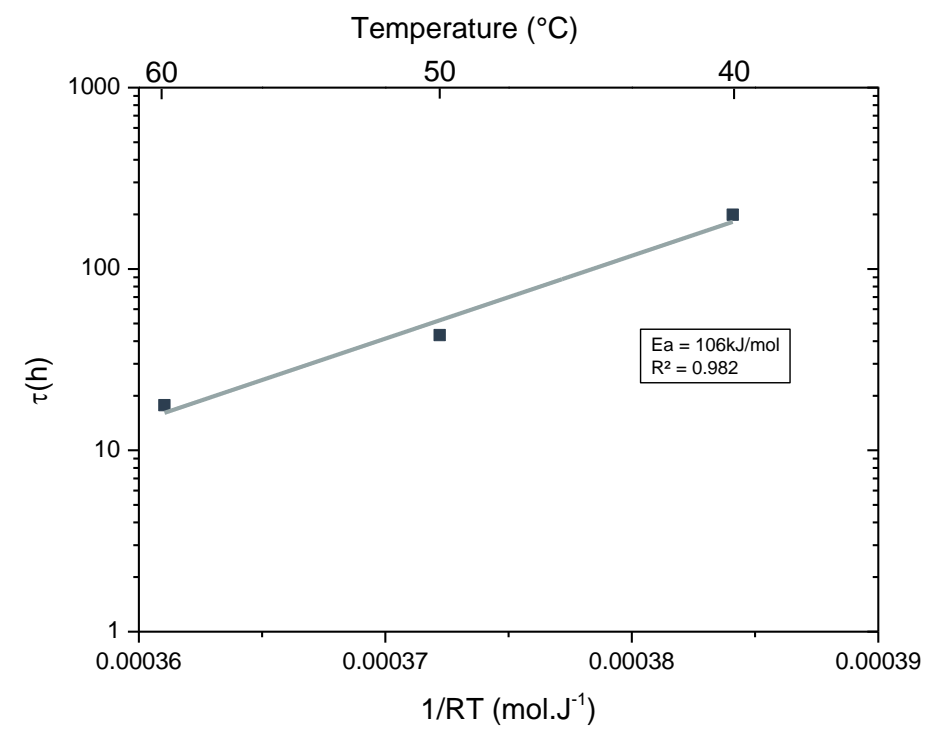

Figure 8: Arrhenius plot of relaxation time

The physical ageing in dry environment (i.e. without any plasticisation of the resin) has been characterized considering maximal stress for ageing temperatures from $40^{\circ} \mathrm{C}$ to $60^{\circ} \mathrm{C}$. The observed increase in maximal stress during ageing can be modelled using a $\mathrm{KWW}$ model and results can be extrapolated to lower temperatures using the Arrhenius expression.

iii) Plasticization of the resin with physically pre-aged samples

In this section, we will focus on the plasticization of the epoxy that has been physically aged previously. Samples were placed in a drying oven at $60^{\circ} \mathrm{C}$ under vacuum for a time equivalent to $t=5 * \tau_{60^{\circ} \mathrm{C}}$, $\tau_{60^{\circ} \mathrm{C}}$ being the relaxation time at $60^{\circ} \mathrm{C}$ (see table 3); so that, according to the $\mathrm{KWW}$ equation, the influence of the physical ageing process on maximum stress has reached more than $80 \%$. This means that the remaining effect during immersion will be relatively minor, less than $20 \%$, and the contribution of plasticization to changes in maximum stress can thus be estimated. No changes in either water content or diffusivity were observed. Tensile results are plotted in Figure 9 . Here again we can observe that the presence of water within the polymer leads to a decrease in maximal stress. In the meantime, it appears that strain at break does not increase in the presence of water when samples are fully physically aged; this was not the case when physical ageing was removed before wet ageing (see Figure $5)$. 


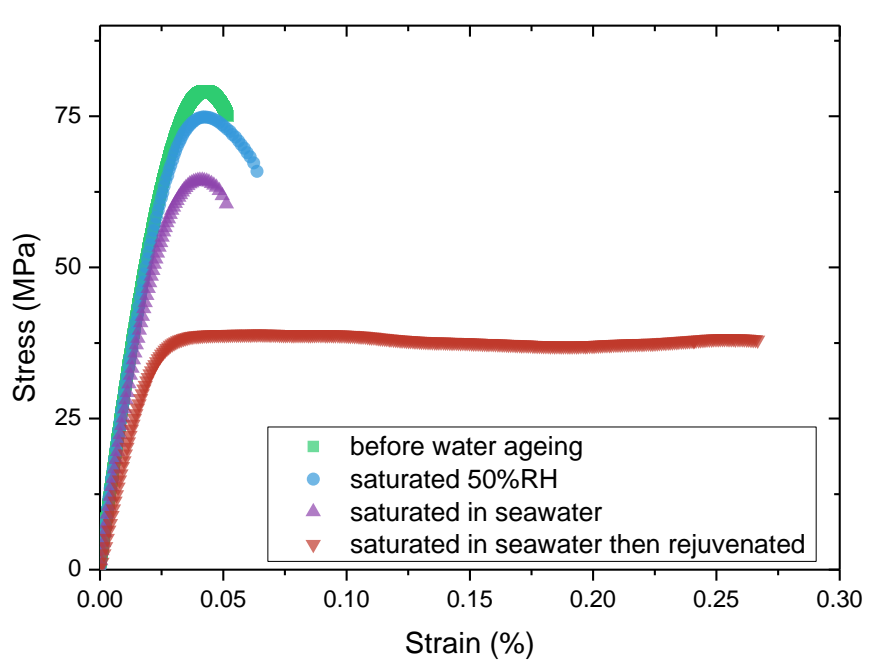

Figure 9: Tensile behaviour of a previously physical aged epoxy subjected to water ageing at saturation

If we focus on maximal stress, it is possible to link the decrease in maximal stress to the increase in mobility through the Tg value, this can be done using the modified Kambour equation [40] (see below); results are plotted on Figure 10.

$$
\sigma=A(T g-T)+B
$$

Where $\sigma$ is the maximal stress in $\mathrm{MPa}, T g$ is the glass transition temperature in ${ }^{\circ} \mathrm{C}, T$ is the testing temperature in ${ }^{\circ} \mathrm{C}$ and $\mathrm{A}$ and $\mathrm{B}$ material properties.

Based on Figure 10, it clearly appears that the decrease in maximal stress due the presence of water (i.e. the slope) is present for both physically and non-physically aged conditions. The physical ageing seems to reduce this effect as a proportionality constant of $0.84 \mathrm{MPa} / \mathrm{K}$ is recorded whereas without physical ageing the value is $1.23 \mathrm{MPa} / \mathrm{K}$. Values recorded in the literature by Cook et al. for different epoxy systems were in the same range [41] but here, the variation is measured without changing the resin chemistry. The main remaining question is now to examine whether there is any effect of water on the physical ageing process, this is the aim of the next section. 


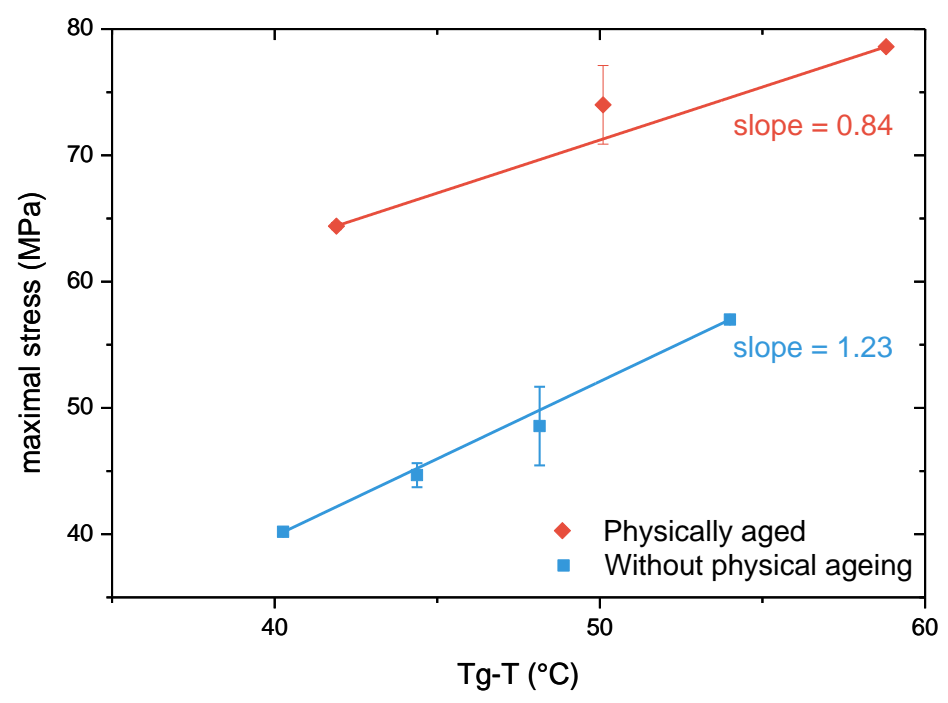

Figure 10: Maximal stress as a function of $\mathrm{Tg}-\mathrm{T}$ induced by water absorption

\section{iv) Physical ageing in presence of water}

This section will investigate how the physical ageing process is affected by the presence of water within the epoxy. Samples were saturated in seawater and then rejuvenated by a 5 minutes thermal treatment at $90^{\circ} \mathrm{C}$ to erase any physical ageing that would have occurred during water absorption. Finally, samples were immersed at different temperatures from 15 to $40^{\circ} \mathrm{C}$ and tested after several durations. Tensile curves as a function of ageing time are plotted in Figure 11. As expected, an increase in maximal stress is observed as a function of ageing duration as well as a decrease in strain at break. This increase in maximal stress is due to physical ageing that occurs in the polymer. It should be noted that sample mass was recorded during ageing and no further weight changes were observed during physical ageing in wet environment.

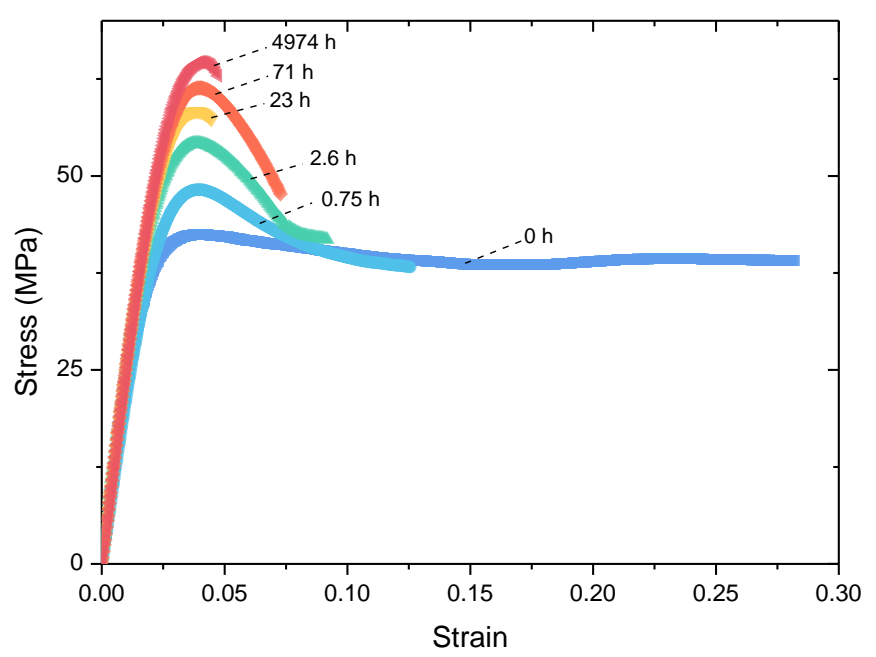

Figure 11: Tensile behaviour of a previously saturated epoxy resin subjected to $40^{\circ} \mathrm{C}$ physical ageing 


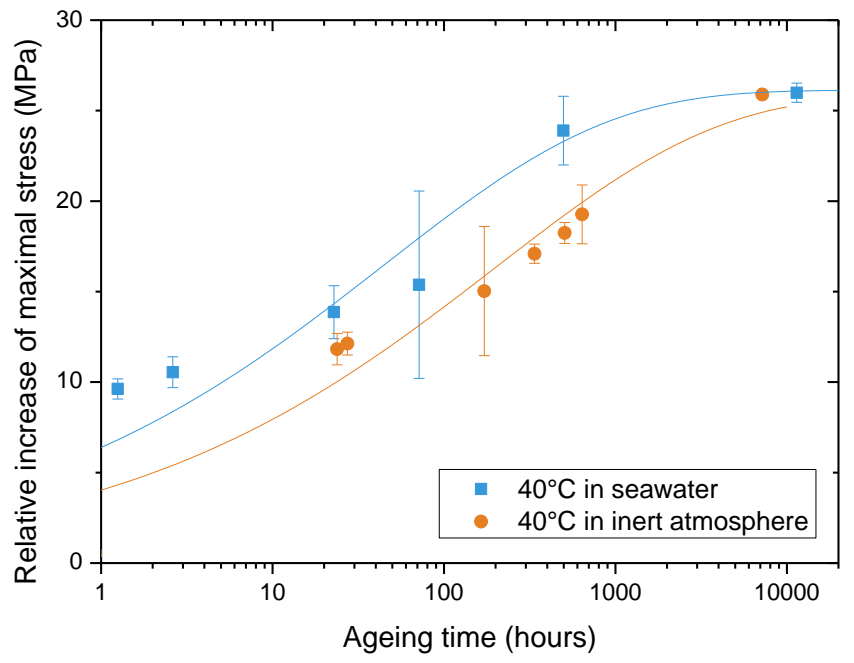

Figure 12: Maximal stress increase as a function of thermal ageing time, in seawater for saturated samples and in inert atmosphere for the dry samples.

Figure 12 shows the increase of maximal stress induced by physical ageing with dry samples aged at $40^{\circ} \mathrm{C}$ and with wet samples aged in seawater at $40^{\circ} \mathrm{C}$. The two main conclusions of this comparison are:

- The physical ageing process occurs to the same extent in the presence of water and with the same shape, in fact an increase of $26 \mathrm{MPa}$ in maximal stress is observed in both cases.

- Physical ageing is much faster in a wet environment. For example, an increase of $11 \mathrm{MPa}$ is measured after 23 hours in air, whereas in water for the same duration, the increase is equal to $14 \mathrm{MPa}$. This behaviour can be explained by the fact that $\mathrm{Tg}$ is decreased by the presence of water from $75^{\circ} \mathrm{C}$ to $60^{\circ} \mathrm{C}$. It means that the difference between the testing temperature and the $\mathrm{Tg}$ is much smaller in water than in air.

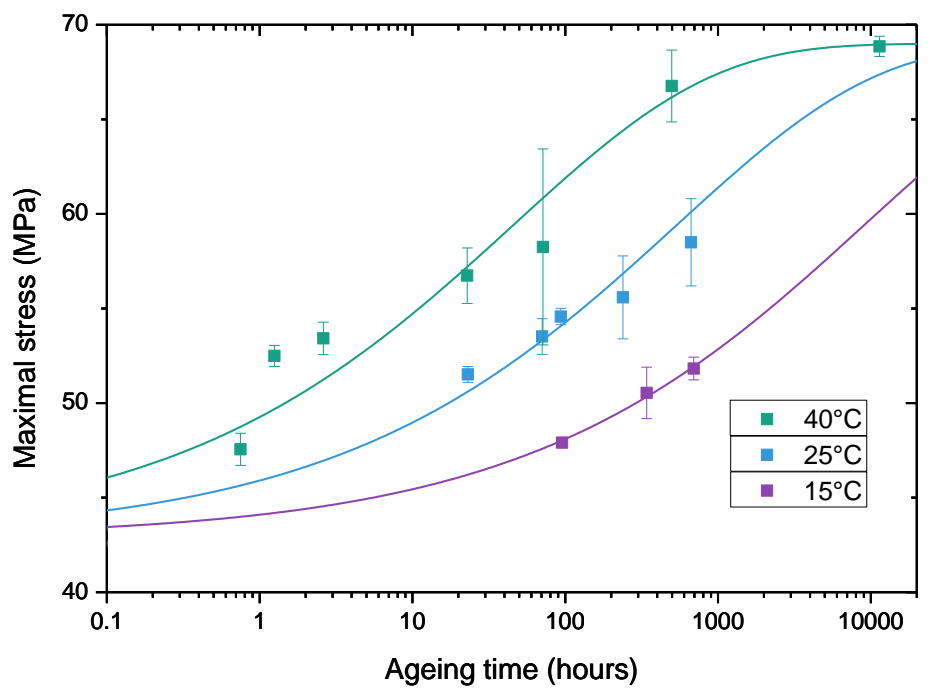

Figure 13: Maximal stress as a function of ageing time of a previously seawater saturated epoxy 


\begin{tabular}{c|c} 
& $\mathbf{T}(\mathbf{H})$ \\
\hline $\mathbf{4 0} 0^{\circ} \mathbf{C}$ & 43 \\
$\mathbf{2 5} \mathbf{C}$ & 919 \\
$\mathbf{1 5}^{\circ} \mathbf{C}$ & 8920
\end{tabular}

Table 3: $\tau$ values obtained during physical ageing of the amine based epoxy in wet environment as function of temperature.

Relaxation times have been determined using the KWW equation (Figure 13) in a wet environment with samples saturated previously, values are shown in Table 3. It appears that the acceleration factor induced by temperature can be, once again, described using an Arrhenius behaviour, see Figure 14 . The activation energy is equal to $160 \mathrm{~kJ} / \mathrm{mol}$, a value that is much higher than in air. The origin of water effect on physical ageing is considered in the next section, dedicated to DMA results.

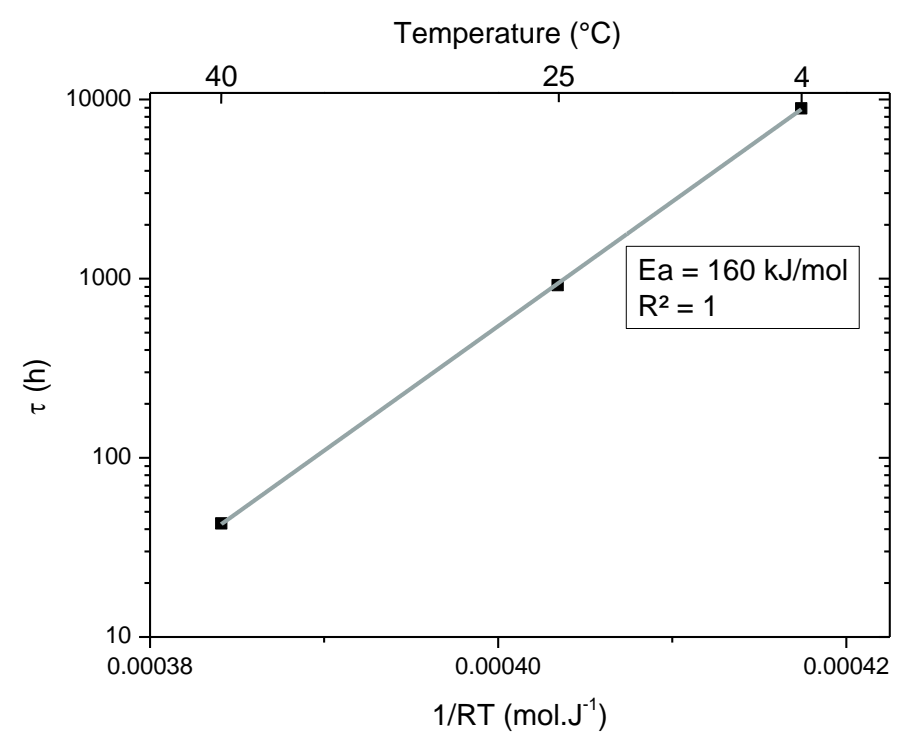

Figure 14: Arrhenius plot of relaxation time for physical ageing process in wet environment

\section{v) Effect of physical ageing and seawater absorption on the beta transition}

Three kinds of samples have been tested by DMA: unaged, samples physically aged in a dry environment at $60^{\circ} \mathrm{C}$ and samples physically aged in seawater at $40^{\circ} \mathrm{C}$. Results are presented in Figure 15. Based on unaged results we clearly see that two transitions occur in the material within the temperature range considered here. First, around $-55^{\circ} \mathrm{C}$ the beta transition occurs, this transition is related to local movement in the polymer. Then, around $+80^{\circ} \mathrm{C}$ the glass transition occurs. After physical ageing in dry environment, no large changes in the two transitions are observed. Only a slight increase of the beginning of the $\mathrm{Tg}$ can be detected. However, when considering samples fully saturated by water two changes occur:

- A decrease in Tg, as already shown in Figure 9; in the presence of water an increase of mobility between macromolecular chains occurs that leads to a $15^{\circ} \mathrm{C}$ drop in $\mathrm{Tg}$ compared to the dry state value.

A change in the Beta transition, in fact we can see that this temperature decreases from $-55^{\circ} \mathrm{C}$ to $-75^{\circ} \mathrm{C}$, and the transition is much more visible after aging in seawater. This behavior has already been observed in the literature [27], where a decrease in beta transition temperature induced by water 
absorption is shown, so this change is not specific to the epoxy studied here but occurs in other amine based epoxies.

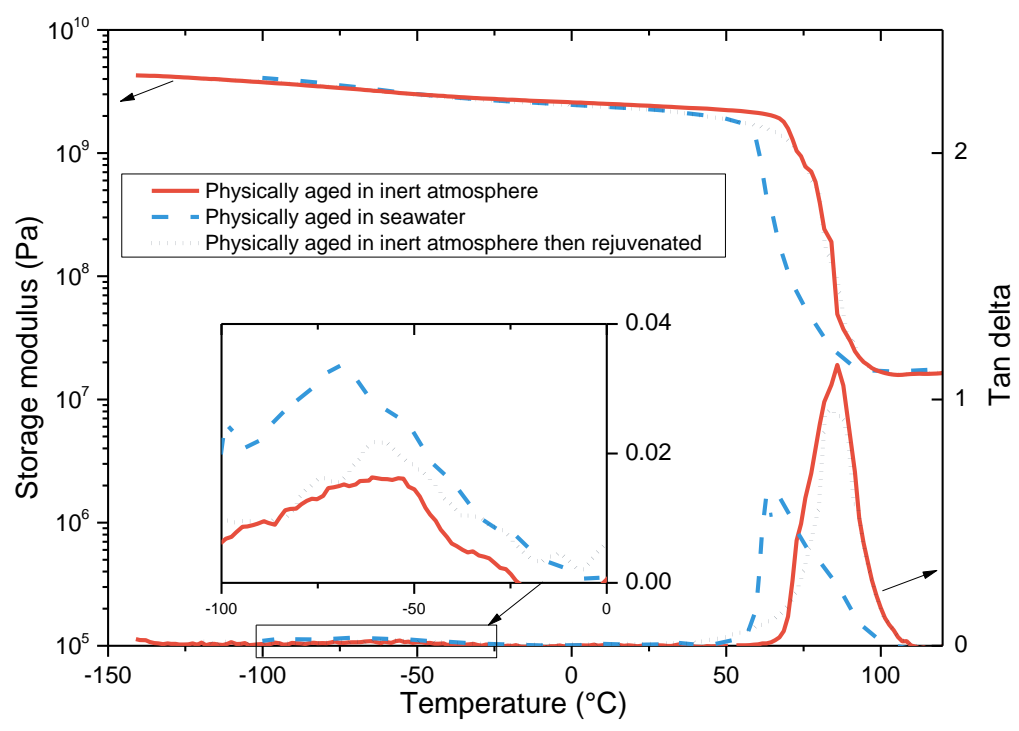

Figure 15: Maximal stress as a function of ageing time of a previously seawater saturated epoxy

Based on these results it can be concluded that the presence of water in epoxy leads to both a decrease in $\mathrm{Tg}$ and modification of $\mathrm{T}_{\beta}$. It is well known that physical ageing is faster when temperature is close to $\mathrm{Tg}$, so when $\mathrm{Tg}$ decreases due to water content it accelerates the degradation process. However, we have seen that more than kinetic rate, the activation energy is affected by the presence of water within the polymer. We can imagine that this behaviour is due to changes in the beta transition. However, the exact role of the beta transition in physical ageing is still not fully understood. This point would need more attention in order to propose a model that is able to predict both plasticization and physical ageing.

\section{Conclusions}

The coupling between physical ageing and plasticization that occurs in amine-based epoxy when in contact with a humid environment has been considered here.

First, based on preliminary results, we have shown that two reversible processes occur when an epoxy is immersed in seawater below Tg: plasticization of the matrix by water and physical ageing. Then a step-by-step study has been performed to evaluate coupling between these two processes.

The plasticization process leads to a large decrease in terms of $\operatorname{Tg}\left(25^{\circ} \mathrm{C}\right.$ for $2.8 \%$ of water) that induces a decrease in maximal stress (from 57 to $40 \mathrm{MPa}$ ). When physical ageing occurs, an increase in maximal stress occurs of $26 \mathrm{MPa}$. Physical ageing has no large effect on the plasticization process.

On the contrary, in the presence of water, which leads to an increase in chain mobility, physical ageing is strongly affected from a kinetic point of view with a large acceleration of the process by a factor of 10 (compared to air). Moreover, the effect of temperature on ageing rate is affected by the presence of water, with an increase of the activation energy from 108 to $160 \mathrm{~kJ} / \mathrm{mol}$. This change in activation might be related to the beta transition that becomes more important when water is present. This requires further study. 
The results from this study highlight the interactions between water plasticization and physical ageing. These effects are present in the range of temperatures commonly used in accelerated aging tests on polymers and polymer composites. It is important that they be considered when defining ageing test strategies, in order to evaluate the proper ageing phenomenon.

\section{Acknowledgment}

The authors would like to thank the French DGA and Ifremer for their financial support. 


\section{References}

1. Nakache M, Aragon E, Belec L, Perrin F-X, Roux G, Le Gac P-Y. Degradation of rubber to metals bonds during its cathodic delamination, validation of an artificial ageing test. Progress in Organic Coatings. 2011;72:279-86.

2. Bouvet G, Trinh D, Mallarino S, Feaugas X, Touzain S. In situ monitoring of organic coating swelling by dynamic mechanical analysis and scanning electrochemical microscopy. Progress in Organic Coatings. 2016;96:13-8.

3. Ilioni A, Gac P-YL, Badulescu C, Thévenet D, Davies P. Prediction of Mechanical Behaviour of a Bulk Epoxy Adhesive in a Marine Environment. The Journal of Adhesion. 2019;95:64-84.

4. Bordes M, Davies P, Cognard J-Y, Sohier L, Sauvant-Moynot V, Galy J. Prediction of long term strength of adhesively bonded steel/epoxy joints in sea water. International Journal of Adhesion and Adhesives. 2009;29:595-608.

5. Graham-Jones J, Summerscales J. Marine Applications of Advanced Fibre-reinforced Composites. Woodhead Publishing; 2015.

6. Gagani Al, Krauklis AE, Sæter E, Vedvik NP, Echtermeyer AT. A novel method for testing and determining ILSS for marine and offshore composites. Composite Structures. 2019;220:431-40.

7. Baley C, Davies P, Grohens Y, Dolto G. Application of Interlaminar Tests to Marine Composites. A Literature Review. Applied Composite Materials. 2004;11:99-126.

8. Colin X, Verdu J. Humid Ageing of Organic Matrix Composites. In: Davies P, Rajapakse YDS, éditeurs. Durability of Composites in a Marine Environment [Internet]. Dordrecht: Springer Netherlands; 2014 [cité 12 juin 2019]. p. 47-114. Disponible sur: https://doi.org/10.1007/978-94007-7417-9_3

9. Morgan RJ, O'neal JE. The Durability of Epoxies. Polymer-Plastics Technology and Engineering. 1978;10:49-116.

10. Delozanne J, Desgardin N, Coulaud M, Cuvillier N, Richaud E. Failure of epoxies bonded assemblies: comparison of thermal and humid ageing. The Journal of Adhesion. 2018;0:1-24.

11. De'Nève B, Shanahan MER. Water absorption by an epoxy resin and its effect on the mechanical properties and infra-red spectra. Polymer. 1993;34:5099-105.

12. El Yagoubi J, Lubineau G, Saghir S, Verdu J, Askari A. Thermomechanical and hygroelastic properties of an epoxy system under humid and cold-warm cycling conditions. Polymer Degradation and Stability. 2014;99:146-55.

13. Bonniau P, Bunsell AR. A Comparative Study of Water Absorption Theories Applied to Glass Epoxy Composites. Journal of Composite Materials. 1981;15:272-93.

14. Morel E, Bellenger V, Verdu J. Structure-water absorption relationships for amine-cured epoxy resins. Polymer. 1985;26:1719-24.

15. Diamant $Y$, Marom G, Broutman $L$. The effect of network structure on moisture absorption of epoxy resins. Journal of Applied Polymer Science. 1981;26:3015-25. 
16. Maggana $C$, Pissis $P$. Water sorption and diffusion studies in an epoxy resin system. Journal of Polymer Science Part B: Polymer Physics. 1999;37:1165-82.

17. Lin YC, Chen X. Moisture sorption-desorption-resorption characteristics and its effect on the mechanical behavior of the epoxy system. Polymer. 2005;46:11994-2003.

18. Nogueira P, Ramírez C, Torres A, Abad MJ, Cano J, López J, et al. Effect of water sorption on the structure and mechanical properties of an epoxy resin system. Journal of Applied Polymer Science. 2001;80:71-80.

19. Moy P, Karasz FE. Epoxy-water interactions. Polymer Engineering \& Science. 1980;20:315-9.

20. Vanlandingham MR, Eduljee RF, Gillespie JW. Moisture diffusion in epoxy systems. Journal of Applied Polymer Science. 1999;71:787-98.

21. Capiel G, Miccio LA, Montemartini PE, Schwartz GA. Water diffusion and hydrolysis effect on the structure and dynamics of epoxy-anhydride networks. Polymer Degradation and Stability.

2017;143:57-63.

22. Abanilla MA, Li Y, Karbhari VM. Durability characterization of wet layup graphite/epoxy composites used in external strengthening. Composites Part B: Engineering. 2005;37:200-12.

23. Sugiman S, Putra IKP, Setyawan PD. Effects of the media and ageing condition on the tensile properties and fracture toughness of epoxy resin. Polymer Degradation and Stability.

2016;134:311-21.

24. Loh WK, Crocombe AD, Abdel Wahab MM, Ashcroft IA. Modelling anomalous moisture uptake, swelling and thermal characteristics of a rubber toughened epoxy adhesive. International Journal of Adhesion and Adhesives. 2005;25:1-12.

25. Fredj N, Cohendoz S, Feaugas X, Touzain S. Some consequences of saline solution immersion on mechanical behavior of two marine epoxy-based coatings. Progress in Organic Coatings.

2010;69:82-91.

26. Mijović J, Zhang H. Local Dynamics and Molecular Origin of Polymer Network-Water Interactions as Studied by Broadband Dielectric Relaxation Spectroscopy, FTIR, and Molecular Simulations.

Macromolecules. 2003;36:1279-88.

27. Colombini D, Martinez-Vega JJ, Merle G. Dynamic mechanical investigations of the effects of water sorption and physical ageing on an epoxy resin system. Polymer. 2002;43:4479-85.

28. Struik LCE. Physical aging in amorphous polymers and other materials [Internet]. 19780000 [cité 7 juin 2019]. Disponible sur: https://www.bcin.ca/bcin/detail.app?id=48813

29. G.'Sell C, McKenna GB. Influence of physical ageing on the yield response of model DGEBA/poly(propylene oxide) epoxy glasses. Polymer. 1992;33:2103-13.

30. Hutchinson JM. Physical aging of polymers. Progress in Polymer Science. 1995;20:703-60.

31. Cook WayneD, Mehrabi M, Edward GrahamH. Ageing and yielding in model epoxy thermosets. Polymer. 1999;40:1209-18. 
32. Zheng Y, Priestley RD, McKenna GB. Physical aging of an epoxy subsequent to relative humidity jumps through the glass concentration. Journal of Polymer Science Part B: Polymer Physics. 2004;42:2107-21.

33. Tchalla ST, Le Gac PY, Maurin R, Créac'hcadec R. Polychloroprene behaviour in a marine environment: Role of silica fillers. Polymer Degradation and Stability. 2017;139:28-37.

34. Hancock BC, Zografi G. The Relationship Between the Glass Transition Temperature and the Water Content of Amorphous Pharmaceutical Solids. Pharm Res. 1994;11:471-7.

35. Kelley FN, Bueche F. Viscosity and glass temperature relations for polymer-diluent systems. Journal of Polymer Science. 1961;50:549-56.

36. Broudin M, Le Gac PY, Le Saux V, Champy C, Robert G, Charrier P, et al. Water diffusivity in PA66: Experimental characterization and modeling based on free volume theory. European Polymer Journal. 2015;67:326-34.

37. Velikov V, Borick S, Angell CA. The Glass Transition of Water, Based on Hyperquenching Experiments. Science. 2001;294:2335-8.

38. Johari GP, Hallbrucker A, Mayer E. The glass-liquid transition of hyperquenched water. Nature. 1987;330:552.

39. Lee A, McKenna GB. The physical ageing response of an epoxy glass subjected to large stresses. Polymer. 1990;31:423-30.

40. Kambour RP. A review of crazing and fracture in thermoplastics. Journal of Polymer Science: Macromolecular Reviews. 1973;7:1-154.

41. Cook WD, Mayr AE, Edward GH. Yielding behaviour in model epoxy thermosets - II. Temperature dependence. Polymer. 1998;39:3725-33. 